\title{
Perceptions of Lecturers on ESP and Academic Proficiency in Nigerian Universities
}

\author{
Chinelo Nwokolo, $\mathrm{PhD}^{*}$ \\ Directorate of General Studies Federal University of Petroleum Resources Warri, Delta State, Nigeria
}

DOI: $10.36348 /$ sijll.2020.v03i11.001

| Received: 18.10.2020 | Accepted: 04.11.2020 | Published: 30.11.2020

*Corresponding author: Chinelo Nwokolo, $\mathrm{PhD}$

\section{Abstract}

The study examined the perceptions of lecturers on the effects of English for specific purposes (ESP) on learner academic proficiency in Nigerian universities, using primary data sourced from a field survey in three selected Nigerian universities. The study was based on the ESP framework and the researcher set an acceptance criterion value of 2.5 for the study. The researcher combined structured interviews and a questionnaire to obtain data from respondents who are all lecturers in Nigerian universities. The data were analyzed with the Likert scale and other statistical tools such as mean, simple percentages and significant ratios. The study calculated a weighted mean value of 3.02 and found that $92 \%$ of the respondents to the interviews identified various ESP language skills as significant factors in enhancing student academic proficiency. Based on the weighted mean value of 3.02 which is greater than the acceptance criterion value of 2.5 , the study observed that to a large extent, ESP has positive effects on academic proficiency of students in Nigerian universities. Following these findings, the study concluded that ESP enhances the performance of undergraduates in their chosen courses of study. It therefore recommended, among others that ESP should become part of compulsory courses in various departments as a way of improving academic proficiency of students in their chosen courses of study.

Keywords: ESP, Nigerian universities, academic proficiency, General English, communications skills.

Copyright (C) 2020 The Author(s): This is an open-access article distributed under the terms of the Creative Commons Attribution 4.0 International License (CC BY-NC 4.0) which permits unrestricted use, distribution, and reproduction in any medium for non-commercial use provided the original author and source are credited.

\section{INTRODUCTION}

In Nigeria, English is predominantly used as a second language (L2) and it performs important functions such as co-official language and medium of instruction at majority of the levels of education. Many Nigerians acquire English after they have acquired a native Nigerian language or Nigerian Pidgin English as first language (L1) and a study by Ahaotu [1] established that the dominant pattern of language acquisition among Nigerian undergraduates is to acquire more English presently; plan to acquire more English in the medium term; and aspiration to raise their children in English. The assignment of significance to the language dates back to when the territory now called Nigeria was colonized by Britain. With colonization, English moved from language of commerce British merchants and Nigerian middlemen to become official language and language of education. These contributed to the growth in significance of English in Nigeria, especially in view of the inability of any of the estimated over 500 indigenous languages to replace it. English is a unique language, functionally and structurally quite different from other languages of the world [2, 3]. Both English for specific purposes
(ESP) and General English language are taught in Nigerian universities under various circumstances. English has been a central subject in the Nigerian formal education system. This is particularly so because of two reasons: it is the medium of instruction at all levels of education beyond primary 4 and it is also a compulsory school subject. At the university level, all undergraduate students are required to pass the compulsory Communication Skills in English before graduation.

The teaching and learning of English in Nigerian universities may be divided into two broad classes: the language specific courses offered in the departments of English and the ESP courses that are offered across all undergraduate disciplines.

ESP means different things to different people. To some people, ESP is described as the teaching of English for any purpose that could be specified or area of specialization in academic discipline. To others, it is described as a special type of English taught and used in academic studies and in specific professional purposes [4]. 
Generally, ESP is an aspect of English for speakers of other languages (ESOL); an umbrella name for a variety of teaching and learning contexts such as English as second language and English as foreign language. This paper focused on ESP in the context of university education, although the term also applies to English for people already in employment. Courses in ESP focus on specific occupations such as: medical profession, law, engineering, economics, accounting, academic English, business, aviation, etc. The study is based on the assumption that ESP may have some impact on the academic proficiency of students and may result in effectiveness and efficiency as is the case with General English. English for academic purposes (EAP) is an ESP course taught to students of undergraduate degrees while other ESP courses include: Business English, Aviation English, Hospitality English, Medical English Legal English, and English for Sports.

Effective communication is an important component of effective professional practice and ESP courses are designed to equip students with the communicative competence to understand and express the content of their various disciplines. This paper categorizes the effective knowledge of the contents of various disciplines as academic proficiency. Academic proficiency refers to the degree of clarity a student attains in the various concepts and topics in the syllabus and his/her ability to apply this in problem solving. Academic proficiency would likely depend on ESP; which is the tool for comprehension and feedback in undergraduate studies. Academic proficiency may aid or impede learners' understanding of the course taught or the vocational skill transferred.

\section{ESP and of Professional Development}

Theoretically, the idea of ESP became popular in the 1960's as it became increasingly obvious that General English courses did not meet learners' and employees' needs of English in specific situations. English dominates global language use and is the global lingua franca of Graddol [5] noted that English is used by approximately 5 billion people across the world. The demand for ESP is therefore growing rapidly, especially in places where English is used as official language, medium of instruction, foreign language, or second language (L2). ESP refers to the teaching and learning of English as a second or foreign language where the goal of the learners is to use English in a particular domain. The term ESP implies that the use of English is specific, and connected to professions, institutional procedures and occupational requirements [6]. People who learn English in order to fulfill the school curriculum requirement, to pass standardized English proficiency tests [such as Test of English as Foreign Language (TOEFL) and International English Language Testing System (IELTS)], or to obtain a promotion or professional development at work, etc. have also grown in number. The ESP framework focuses on training and learning that targets identified specific needs of learners as opposed to general language knowledge. An ESP course design would cater for the needs of such learners seeking professional or academic development than a General English course design.

\section{LITERATURE REVIEW}

The acronym ESP describes the kind of English used in academic studies and the vocational or professional purposes [7]. Some of the characteristics of ESP distinguish it from General English. First, ESP is designed to meet the professional needs of the learners and improve their problem solving skills. But General English focuses on the knowledge of linguistic forms of the language. Secondly, ESP utilizes the methodology and practices of the various disciplines it serves and focuses on the appropriate structures of grammar, lexis, register, study skills, discourse, etc. for these [4]. ESP is different from General English teaching: ESP seeks to develop the communication skills of undergraduates while General English seeks to improve linguistic knowledge. Susilowati [8] summarized the principles and the methods of ESP in the following words: "The popular principle of English for Specific Purposes (ESP) is 'Tell me what you need English for and I will tell you the English that you need". This principle suggests that ESP is an approach to language teaching which is oriented to fulfil learners' needs.'

Hutchinson and Waters [9] defined ESP as an approach rather than a product -meaning that ESP does not just involve a particular kind of language, teaching material or methodology. Strevens' [4] made the following distinctions between definition of ESP and General English:

- Absolute characteristics: language teaching is designed to meet specified needs of the learner; related in content to particular disciplines, occupation and activities; centered on the language appropriate to those activities in syntax, text, discourse, semantics, etc., and analysis of the discourse; designed in contrast with General English)

- Two variable characteristics: 1. ESP may be restricted to the language skills to be learned, (e.g. reading). 2. It may not be taught according to any pre-ordained methodology).

Robinson [10] defined ESP based on two criteria. The first criterion views ESP as normally 'goaldirected'. The second criterion describes ESP courses as aiming to specify learner needs through the medium of English with a number of characteristics that explain that ESP courses are hampered by a limited time for the realization of course objectives and are taught to adults in homogenous classes in terms of the work or specialist studies that the students are involved in. 
Islam and Khan [11] investigated the factors that influence successful delivery of EAP instruction in the tertiary level of education in Bangladesh and found that both the medium of instruction and other factors (such as a foreign language learning anxiety, attitude of both instructors and learners, methods of instruction, and patterns of verbal communication between teacher and student) also play vital roles in achieving successful interaction in the EAP classroom. They concluded that Bangladeshi universities should consider adjustment of curriculum and pedagogy modifications and innovations that would achieve a more effective model of instruction processing.

\section{Types of English for Specific Purposes (ESP)}

Since teachers and researchers of ESP are interested in the distinctive features of the English language determined by the profession or branch of knowledge where the learners will function as L2 users, it is possible to separate many types of ESPs, such as: Medical English, English for IT, and English for Law, English for Tourism, Business English, etc.). However, there are different opinions on the classification of ESP. Carter [12] identified three types of ESP and these are:

1) English as a restricted language,

2) English for Academic and Occupational Purposes

3) English with specific topics.

On the other hand, Hutchinson \& Waters (1987) provided the "tree of ELT" where ESP is divided into three branches:

a) English for Science and Technology (EST),

b) English for Business and Economics (EBE),

c) English for Social Studies (ESS).

They further divided each of these branches into English for Academic Purposes (EAP) and English for Occupational Purposes (EOP), but acknowledged that EAP and EOP are not strictly separated as evidenced in people who study and work simultaneously. Both EAP and EOP serve the same purpose of employment, although their means of achieving same are different. Kennedy and Bolitho [13] identified ESP according to the need of scientists and technologists. This type is called English for Science and Technology (EST). This component of EOP is suitable for learners who need to use English in their profession, whether the learning happens before; during or after the time the learners are being trained for the profession [13]. However, the timing of training may affect the content of the programme. For instance, the content of an English program for a trainee secretary will be different from a program for another secretary who is already employed but needs to improve his/her communication skills in English.

EAP is taught generally in Nigerian higher institutions of learning because students require English in their studies. The language components taught may be based on the specific disciplines and may include the learning of study skills (listening to lectures, taking notes, writing reports, reading textbooks university level studies. The role of English across the various disciplines is to provide access to knowledge contained in textbooks, periodicals, and journals, reports, and abstracts and the effective communication of the knowledge so obtained. The latter may be in the forms of presentation of new knowledge such as papers, university theses, longer reports, articles in scientific journals, and others.

Fitria [6] examined the context of Business English as a part of ESP to economics students through content analysis. The study concluded that teaching Business English requires a teacher's awareness of the subject matter. Fitria [6] also identified three basic benefits of ESP and these are learning speed, learning efficiency, and learning effectiveness. First, ESP results in faster acquisition of target linguistic forms because it is similar to the pattern of native-speaker acquisition of language for specific purposes. The pattern allows ESP students to learn selected content, when they need it, and in authentic, content-based contexts. ESP does not only follow this pattern, but also enhances it through the provision of opportunities to learn in an accelerated, intensive context [14]. Secondly, ESP courses improve learning efficiency by helping students to make maximal use of learning resources because the resources are pre-selected and concentrated towards the acquisition of specific, pre-identified linguistic items and skills. Thirdly, ESP courses enhance learning effectiveness for both university students and persons in employment. Unlike in General English, only language and communication structures relevant to the needs of the learners are included in the course and the learners find opportunities of practice even while the learning is going on. The integration of learning and practice enhances the effectiveness of the learning experience.

Nwokolo and Ahaotu [15] distinguished between EAP and General English and noted the relegation of the interest of students with language disorders in the delivery of EAP in Nigeria. In their words;

A unique feature distinguishes EAP from other designations of English language courses: EAP is trans-disciplinary and focuses on the advancement of communication skills of candidates of diverse backgrounds while regular English courses focus on the development of language knowledge. Overall, the expected learning outcome of EAP is the advancement of the communication skills of the student. Through this, EAP has the potential of advancing graduate employability and professional development because efficient communication skill is considered 
one of the topmost skills in employability and career advancement. Unfortunately, the peculiar needs of students with language disorders have not been provided in the delivery of EAP courses and this hinders their realization of the learning outcome. Nwokolo \& Ahaotu [15].

The present study establishes a nexus between the observations above and their remediation by seeking the views of lecturers on the impact of ESP on academic proficiency of their students.

ESP may be further contrasted with General English courses. While ESP courses are definitely focused only on language required in a course or profession, General English courses deal with many different topics at superficial levels. General English also deals with many different skills and typically attempts to give equal treatment to each. As a result, General English courses are spread over long periods and are useful in non-specific situations. However, learners with specific learning needs require less general and shorter courses that offer sufficient depth and ESP provides this.

Bhatia, Anthony, and Noguchi [16] examined the theory and practice of ESP in Asia and observed a necessity for English to fulfil specific goals of its users since it has become an Asian language. To buttress the increasing significance of ESP courses, they noted as follows:

Most of the traditional models of language education have become grossly inadequate to meet the challenges of the present-day interdisciplinary demands and practices of the academy and the world of professions. These challenges have emerged as a result of several developments, some of which include, the growing tensions between the world of work and that of the academy, the complexities of the modern multi-media encouraging creative forms of information design and presentation, the increasing interdisciplinary nature of most university academic programmes, [16].

This view relates the improvement of academic proficiency to communication skills and aligns with the objective of the present study. ESP seeks effective methods of delivering competencies required in academics and professions.

Some ESP experts suggest a "two layer" ESP course design: one that covers generic knowledge in a specific profession and another that focuses on individual specialization [17]. This view raises three points of enquiry. First, is there any significant nexus between ESP and academic proficiency? Also, to what extent does ESP affect the academic proficiencies of learners in Nigerian universities? Thirdly, are there factors that affect academic proficiency as it relates to ESP in Nigerian universities? It is against this backdrop, that the study investigated lecturers' perspectives on the extent to which ESP has impacted on undergraduate academic proficiency in Nigerian universities.

\section{Statement of Problem}

English performs many important functions in education and communication in Nigeria, including its role as medium of instruction in universities. This implies that students' proficiency level in the language may have significant impact on their general academic proficiency level. Consequently, challenges abound in the teaching and learning of English for specific purpose as it relates to different academic discipline across Nigerian university. These challenges include English language pronunciation, spelling inconsistency, disjointed, grammatical errors and ambiguity in formulation of English language. This paper draws attention to such challenges and elements affecting the English for specific purpose. This affects the academic proficiency and consequently affects the ability of the listeners and learners to comprehensively understand the course content.

\section{Research Questions}

The following research questions guided the study:

i. Is there any nexus between ESP and academic proficiency in Nigerian university?

ii. To what extent ESP affect academic proficiency in Nigerian university?

iii. What are the factors that affect academic proficiency as it relates to ESP in Nigerian universities?

\section{Aim and Objectives of study}

The specific aim of this study is to determine the perceptions of lecturers on the impact of ESP on academic proficiency of undergraduates in Nigerian universities. The objectives of the study are:

i. To investigate the nexus between ESP and academic proficiency in Nigerian university

ii. To examine the extent to which ESP affect academic proficiency in Nigerian university

iii. To identify factors that affect academic proficiency as it relates to ESP in Nigerian university.

\section{Limitations of the Study}

The study is delimited to only three universities in the Southern part of Nigeria because of both logistic and security concerns of a broader based study. As a result, the result obtained in this study may differ if it were conducted in a broader demographic area and from a larger population of respondents.

\section{Significance of the study}

The study will bring to the limelight in-depth understanding of nexus between ESP and academic 
proficiency in Nigerian university. It will guide educators' especially English language teachers in teaching, monitoring, and evaluation of students ${ }^{\text {ee }}$ performances. The study will highlight the need for an integrative approach in English for specific purpose in learning. The study was carried out in three Nigerian university located in Delta state. The universities were randomly selected as a representative of three categories of Nigerian universities. These categories are: Federal, State, and Private Universities.

\section{METHODOLOGY}

This study adopts a survey research design, primarily relied on descriptive techniques, drawing from a comprehensive desk review and field research conducted for this specific analysis which focuses on the extent to which ESP affect academic proficiency in Nigerian university. The field research utilized qualitative and quantitative research methods for collecting cross sectional data on the effect of ESP on academic proficiency in Nigerian university. The crosssectional data was sourced via questionnaire instrument and semi-structured interview. While, secondary information was sourced from relevant published and unpublished literature. Thereafter, both quantitative and qualitative data are triangulated for better research results. The primary data collected is measured on various scale ranges from nominal, ordinal and interval scale.

The target population of this study comprises the entire academic staff of Nigerian university. However, due to the large population of these sets of people a manageable sample size is required. Therefore, a sample is selected from the population using a formula as suggested by Godden [18] as:

$$
S=\frac{Z^{2} p(1-p)}{C^{2}}
$$

Where: $\mathrm{S}=$ the sample size, $\mathrm{P}=$ Percentage of success, $\mathrm{C}=$ Confidence interval and $\mathrm{Z}=$ Confidence level. With $90 \%$ level of confidence (corresponding value of 1.645) and a confidence interval of $0.01(10 \%)$ and Percentage of success is $50 \%$, the sample size is calculated thus:

$$
S=\frac{(1.645)^{2} \times 0.5 \times 0.5}{(0.01)^{2}}=67.65 \approx \text { sixty- }
$$

eight (68) respondents is the target.
Following the sample size determined, the multi-stage sampling technique was adopted, in the first stage; the stratified sampling technique was used to divide the sample into three proportionate categories such that each stratum represents each of the areas being used for this study. The researcher selected one federal university, one state university and one private university. A total of 68 academic staff of the following schools was used: (i) Federal University of Petroleum Resources Warri, (ii) Delta State University Abraka and, (iii) Admiralty University of Nigeria Ibuso/Asaba.

After that, the purposive technique was used to draw 24, 22 and 22 respondents' from the three university mentioned earlier to each stratum to make up the sample size of 68. In the second stage, randomly sampling technique was employed to select the respondents who could provide information on the effect of ESP on academic proficiency in Nigerian university in the study area. Random sampling technique allows equal participation by every element of the population.

\section{Model Specification}

The analysis was carried out to estimate the functional linear association between the predictors and responses. Thus, the specified functional relationship is formulated as follows:

$$
\begin{aligned}
& \mathrm{AP}=\mathrm{f}(\mathrm{ESP}) \\
& \mathrm{AP}=(\mathrm{LS}+\mathrm{LEC}+\mathrm{LEV}) ; \mathrm{ESP}=(\mathrm{RD}+\mathrm{WR}+\mathrm{SP} \\
& +\mathrm{LS}) \\
& \mathrm{AP}=\beta_{0}+\beta_{1} \mathrm{X}_{1} \mathrm{RD}+\beta_{2} \mathrm{X}_{2} \mathrm{WR}+\beta_{3} \mathrm{X}_{3} \mathrm{SP}+\beta_{4} \mathrm{X}_{4} \mathrm{LS}+\mu \ldots \ldots \ldots \ldots . .(2)
\end{aligned}
$$

Where;

AP, stand for academic proficiency. This refers to the level of clarity students have about the various concepts and topics in the syllabus and their ability to apply this to solve the situational questions. In this study is measure by three-factor responses which are learning speed (LS), learning efficiency (LEC) and learning effectiveness (LEV). ESP represents English for specific purposes. This refers to the teaching and learning of English as a second or foreign language where the goal of the learners is to use English in a particular domain. In this study is measured by the communication skill of the tutor in delivery of lecture in terms of reading (RD), writing (WR), speaking (SP) and listening (LS).

$\beta_{0}=$ intercept, $\beta_{1}, \beta_{2} \beta_{3}$ and $\beta_{4}$ are the parameters estimate; $\mu=$ Measurement error.

A prior expectation $\beta_{1}, \beta_{2} \beta_{3}$ and $\beta_{4}>0$ 


\section{DATA ANALYSIS TECHNIQUE}

The data collected were subjected to a series of treatment; coded, translated, analyzed and tested using simple percentage. They are presented, for simplicity, using appropriate tables, charts, graph as well as texts with the aid of statistical package for social science (SPSS version 23).

\section{Data Presentation and Analysis}

This section presented the data, analyzed and discussed the result. The result and data analysis are presented in the Tables 1- 5 below. A total of sixtyeight (68) sets of questionnaire were distributed, out of which 60 sets of questionnaire were duly filled, returned and were found valid for data analysis.

Table-1: Questionnaire Distributed and Retrieval

\begin{tabular}{|c|c|c|c|}
\hline Areas Studied & $\begin{array}{l}\text { Number } \\
\text { Administered }\end{array}$ & $\begin{array}{l}\text { Number } \\
\text { Returned }\end{array}$ & $\begin{array}{l}\text { Percentage } \\
\text { Returned }\end{array}$ \\
\hline Federal University of Petroleum Resources Warri & 24 & 22 & $37 \%$ \\
\hline Delta State University Abrakka & 22 & 18 & $30 \%$ \\
\hline Admiralty University of Nigeria Ibuso/Asaba & 22 & 20 & $33 \%$ \\
\hline Total & 68 & 60 & $100 \%$ \\
\hline
\end{tabular}

Source: Researcher's (2020) Computation

Table 1 above shows that 22 represent 37 percent of the respondents were from Federal University of Petroleum Resources Warri and 18 represents $30 \%$ were from Delta State University Abrakka while the remaining 20 represent $33 \%$ of the respondents were from Admiralty University of Nigeria Ibuso/Asaba. The total of 60 returned questionnaires were used for the analysis without preferences for number returned in each of the University. More so, qualitative data via telephone interview was sourced to support or buttress the responses from questionnaire. Table 2 present the demographic characteristic of the respondents as follows,

Table-2: Demographic Characteristics of the Respondents

\begin{tabular}{|l|l|l|l|}
\hline & Response & Frequency & Percent (\%) \\
\hline $\mathbf{1 .}$ & Sex: Male & 40 & 67.0 \\
\hline & Female & 20 & 33.0 \\
\hline & Total & $\mathbf{6 0}$ & $\mathbf{1 0 0 . 0}$ \\
\hline $\mathbf{2}$ & Age range : 21-25 $26-30$ & 9 & 15.0 \\
\hline & \multicolumn{1}{|c|}{$31-35$} & 15 & 25.0 \\
\hline & $36-$ above & 16 & 28.0 \\
\hline & \multicolumn{1}{|c|}{20} & 33.0 \\
\hline & Total & $\mathbf{6 0}$ & $\mathbf{1 0 0 . 0}$ \\
\hline $\mathbf{3}$ & Marital Status: & & \\
\hline & Single & 25 & 42.0 \\
\hline & Married & 35 & 58.0 \\
\hline & Total & $\mathbf{6 0}$ & $\mathbf{1 0 0 . 0}$ \\
\hline $\mathbf{4}$ & Educational Attainment: & & \\
\hline & Master (MSc) & 7 & 12.0 \\
\hline & Doctor (PhD) & 42 & 70.0 \\
\hline & Associate Professor (Assoc Prof) & 5 & 8.0 \\
\hline & Professor & 6 & 10.0 \\
\hline & Total & $\mathbf{6 0}$ & $\mathbf{1 0 0 . 0}$ \\
\hline
\end{tabular}

Source: Researcher field work 2020 Computation

Table 2 presents demographic characteristics of the respondents. The survey result shows that both males and females participated in the study. The total observation is sixty (60). While the male participants recorded forty (40) representing 67 percent of the respondents, the female participants recorded twenty (20) representing approximately 33 percent. With this data distribution, both male and female genders have been given opportunity to freely express their opinion on the subject matter.
Furthermore, the table 2 shows that the age bracket of the participants in the study in the following range: 21 - 25, 26 - 30, 31 - 35, 36 and above. However, the result reveals that age bracket 36 - above recorded highest number of participants which represent approximately 33 percent, followed by age bracket 36 and above and $31-35$; which recorded participants' numbers of 16 and 15 , representing approximately 28 and 25 percent respectively. Lastly, the age bracket 21 25 with 9 participants represents approximately 15 percent. 
In addition, table 2 reports the marital status of the participants. The table 2 shows that 25 respondents representing approximately 42 percent were single while 35 respondents representing 58 percent were married. This implies that both the single and the married provided information on the subject matter. Lastly, table 2 present the educational attainment of the participants. The table 2 shows that 7 participants representing 12 percent of the respondents attained master's degree level of education while 42 participants representing 70 percent of the participants obtained doctorate degree. It further indicated that 5 participants representing 8 percent of the respondents have attained the rank of associate professor, while the remaining 6 participants representing 10 percent of the participants were of the rank of full professor. This suggests that majority of the targeted respondents were qualified to participate in the study.

\section{Test of Research Questions}

The research questions that guided this study were tested in the following section:

Research Question 1: Is there any nexus between ESP and academic proficiency in Nigerian universities? The answers is presented in table 3 as follows

Table-3: Nexus between ESP and Academic Proficiency in Nigerian universities

\begin{tabular}{|c|c|c|c|}
\hline Responses & Frequency & Percentage & Comments/Decision \\
\hline Yes & 45 & $75 \%$ & \multirow{4}{*}{$\begin{array}{l}\text { Overall, the total percentage of the respondents who answered "yes" is } \\
\text { higher than those respondents that answered (no and no idea). Thus, the } \\
\text { decision to accept that there is nexus between ESP and academic } \\
\text { proficiency in Nigerian university is based on } 75 \% \text { of the total responses. }\end{array}$} \\
\hline No & 10 & $17 \%$ & \\
\hline No idea & 5 & $8 \%$ & \\
\hline Total & 60 & $100 \%$ & \\
\hline
\end{tabular}

Source: Researcher field work 2020 Computation

Research Question 2: To what extent ESP affect academic proficiency in Nigerian universities? The responses are presented in table 4 in four Likert scale ranges from very great extent $(\mathrm{VGE})=4$, great extent $(\mathrm{GE})=3$, little extent $(\mathrm{LE})=2$, and very little extent $(\mathrm{VLE})=1$, as follows:

Table-4: Extent of the effects of ESP on Academic Proficiency in Nigerian universities

\begin{tabular}{|l|l|l|l|l|l|}
\hline Responses & VGE & GE & LE & VLE & Criterion/Decision to Accept or Reject \\
\hline Ranking & 4 & 3 & 2 & 1 & \begin{tabular}{l} 
10/4 2.5 (criterion) \\
\hline Frequency
\end{tabular} \\
\cline { 1 - 5 } Weighted & 60 & 35 & 6 & 4 & $\begin{array}{l}\text { Accept that to an extent ESP have effects on Academic } \\
\text { Proficiency in Nigerian universities if weighted mean } \\
\text { is greater than criterion value. Otherwise, reject. } \\
\text { Decision: based on the weighted mean value of } 3.02 \\
\text { which is greater than criterion value of } 2.5 \text { it can be } \\
\text { concluded that to a large extent ESP have effects on } \\
\text { Academic Proficiency in Nigerian universities. }\end{array}$ \\
\hline
\end{tabular}

Source: Researcher field work 2020 Computation university?

Research Question 3: What are the factors that affect academic proficiency as it relates to ESP in Nigerian

Table-5: Factors that Affect Academic Proficiency: ESP in Nigerian

\begin{tabular}{|c|c|c|c|}
\hline Responses & Frequency & Percentage & \multirow{7}{*}{$\begin{array}{l}\text { Comments/Decision } \\
\text { The responses show that } 20 \text { respondents which represent } 33 \text { percent } \\
\text { recorded highest figure of participants who identified specking as a } \\
\text { factor that affect academic proficiency as it relates to ESP in Nigerian } \\
\text { universities. Also, } 15 \text { respondents representing } 25 \text { percent identified } \\
\text { writing as a factor that affects academic proficiency in ESP in Nigerian } \\
\text { universities. Subsequently, } 12 \text { respondents represent (or } 20 \% \text { of } \\
\text { respondents) identified reading as a factor that affects academic } \\
\text { proficiency as it relates to ESP in Nigerian universities. More so, } 8 \\
\text { respondents representing } 13 \text { percent identified listening as a factor that } \\
\text { affects academic proficiency in ESP in Nigerian universities. Lastly, } 5 \\
\text { respondents which represent } 8 \text { percent identified others factors not } \\
\text { listed in the questionnaire options but mentioned during the structured } \\
\text { interviewed as factors that affect academic proficiency in ESP in } \\
\text { Nigerian universities }\end{array}$} \\
\hline Reading & 12 & $20 \%$ & \\
\hline Writing & 15 & $25 \%$ & \\
\hline Speaking & 20 & $33 \%$ & \\
\hline Listening & 8 & $17 \%$ & \\
\hline Others & 5 & $8 \%$ & \\
\hline Total & 60 & $100 \%$ & \\
\hline
\end{tabular}

Source: Researcher field work 2020 Computation 


\section{CONCLUSION}

The study examined the effects of ESP on academic proficiency of students in Nigerian universities, using primary data sourced from a field survey conducted in three selected Nigerian universities that included federal, state and private universities. The combination of structured interviews and questionnaires enabled the researcher to assess disparate dimensions of the perspectives of the respondents on the subject. The study finding at these two levels reveals that there is significant relationship between ESP and academic proficiency of students in Nigerian universities. Furthermore, that ESP has positive and significant effect on academic proficiency in Nigerian universities is an attestation to previous scholarship that underpinned English as an important tool for professional and national development in Nigeria [1921]. Also, the study findings revealed that speaking and writing skills in ESP are the most influential factors of academic proficiency while reading, listening, and other factors also contribute but to a lesser degree.

In the study, $92 \%$ of the respondents to the interviews identified various ESP skills as significant factors in enhancing student academic proficiency and these included the four language skills of writing, speaking, reading, and listening. Based on the weighted mean value of 3.02 (also obtained from the study: see Table 4 above) which is greater than the acceptance criterion value of 2.5 , the researcher observed positive effects of ESP on academic proficiency of students in Nigerian universities based on the opinions of the respondents. Following these findings, the study hereby concludes that ESP enhances the performance of undergraduates in their chosen courses of study in Nigerian universities.

\section{RECOMMENDATIONS}

Based on the above findings and conclusion, the researcher makes the following recommendations:

1. ESP should become part of compulsory courses in various departments as a way of improving academic proficiency of students in their chosen courses of study. This would augment the present practice of teaching General English at first year level across Nigerian universities by providing additional specific content that would develop the students' professional competence.

2. More research should be encouraged on the subject of ESP. Additional understanding of the effects ESP has on academic proficiency in Nigerian universities will provide a better platform for policy makers to formulate and implement appropriate policy that will checkmate inefficiency of the application of ESP and consequently, address the issues of quality control in education.

3. Following the findings of this study, it is possible to enhance the overall quality of graduates of Nigerian universities through the instrument of
ESP. One of the ways of achieving this is by assisting undergraduates to cope with content through a more diversified ESP content that focuses on specific disciplines throughout the course of study.

\section{REFERENCES}

1. Ahaotu, J. O. (2020). English versus indigenous Nigerian languages: Trends in language acquisition among students of University of Port Harcourt, Nigeria. African Research Review: $A n$ International Multidisciplinary Journal (AFRREV), 14(2), Serial number 58, April, 2020: 79-93. DOI: http://dx.doi.org/10.4314/afrrev.v14i2.8

2. Umera-Okeke, N. P., \& Ahaotu, J. O. (2018). Perspectives on the socio-pragmatics of English in Nigeria. Port Harcourt: Sofiata Publishers.

3. Anyanwu, E. C. (2016). Socio-Cultural influences on effective English communication of Nigerian undergraduates. Mgbakoigba, Journal of African Studies, 6(1), $1-8$.

4. Dudley-Evans, T. (1998). Developments in English for Specific Purposes: A multi-disciplinary approach. Cambridge University Press.

5. Graddol, D. (2006). English next: Why global English may mean the end of 'English as foreign language'. The UK: the English Company.

6. Fitria, T. N. (2019). Business English as a part of teaching English for Specific Purposes (ESP) to economics students. Journal Education and Economics (JEE), 02(02), 143 - 152.

7. Anthony, L. (1997). English for Specific Purposes: What does it mean? Why is it different? Retrieved September 2020 from: https://www.researchgate.net/publication/26763130 4_English_for_specific_purposes_What_does_it_m ean_Why_is_it_different

8. Susilowati, E. (2008). ESP as an Approach of English Language Teaching in ITS. Jurnal Sosial Humaniora, $\quad$ 1(1). 66-75. from:https://www.researchgate.net/publication/314 098361_esp_as_an_approach_of_English_languag e_teaching_in_ITS.

9. Hutchinson, T., \& Waters, A. (1987). English for Specific Purposes: A learner-centered approach. Cambridge: Cambridge University Press.

10. Robinson, P. C. (1991). ESP today: A practitioner's guide. Prentice Hall.

11. Islam, R., \& Khan, M. (2019). Factors affecting medium of instruction on undergraduate EAP courses in private universities of Bangladesh. Professional and Academic English: Journal of the IATEFL English for Specific Purpose Special Interest Group. 53. 4-9.

12. Carter, D. S., \& Goldman, B. D. (1983). Antigonadal effects of timed melatonin infusion in pinealectomized male Djungarian hamsters (Phodopus sungorus sungorus): duration is the 
critical parameter. Endocrinology, 113(4), 12611267.

13. Kennedy, C., \& Bolitho, R. (1984). English for specific purposes. Macmillan Pub Ltd.

14. Wright, C. (1992). The benefits of ESP: Cambridge Language Consultants. Retrieved December, 2018 from https://www.camalang.com/art001.htm

15. Nwokolo, C., \& Ahaotu, J. (2019). Enhancing the learning outcome of EAP students with language disorders: A proposal. Working Papers: Journal of English Studies, 8(2). 210-218.

16. Bhatia, V., Anthony, L., \& Noguchi, J. (2011). ESP in the 21st century: ESP theory and application today. Proceedings of the JACET 50th Commemorative International Convention. Retrieved September, 2020 from: https://www.researchgate.net/publication/26763141 6_ESP_in_the_21st_century_esp_theory_and_appli cation_today. 1-9.
17. Tenieshvili, A. (2019). Towards various aspects of teaching language for specific purposes at higher education institutions. Journal of Foreign Language Education and Technology: 111-126.

18. Godden, B. (2004). Sample size formulas Retrieved February 2020 from: http:williamgodden.com/samplesizeformula.pdf.

19. Emenanjo, N. E. (2010). Functional illiteracy: The bane of national development. In English studies and national development in Nigeria. Ndimele, O.m. (Ed). Port Harcourt, ELTAN and M \& J Grand Orbit Communications Ltd.1-32

20. Lanier, W. (2010). Speech disorders. Farmington Hill: Lucent Books.

21. Law, J. (1992). What is language impairment? In Law, J. (Ed). The early identification of language impairment in children: Therapy in practice 30. London: Springer- Science+Business Media. 